\title{
Sigmoid perforation caused by a migrated biliary stent and closed with clips
}

A 73-year-old man was admitted with sharp tenderness in the left iliac fossa, peritonitis, fever, and leukocytosis. The patient had undergone an endoscopic retrograde cholangiography 15 days earlier, which showed choledocholithiasis and benign biliary stricture. The stones were extracted and a $10-\mathrm{Fr}, 12-\mathrm{cm}$ plastic biliary stent was inserted. A computed tomography (CT) scan revealed that the biliary stent had migrated and caused sigmoid colon perforation with mild pneumoperitoneum ( Fig. 1 ). Sigmoidoscopy was carried out after colon preparation with enema. It showed extensive diverticulosis in the sigmoid colon and the stent was $30 \mathrm{~cm}$ from the anus. Its tip had perforated the wall of the sigmoid colon, near the diverticula ( $\bullet$ Fig. 2 ). The stent was atraumatically removed with foreign body forceps. A punctate perforation ( Fig. 3) was closed with two throughthe-scope clips and an endoloop

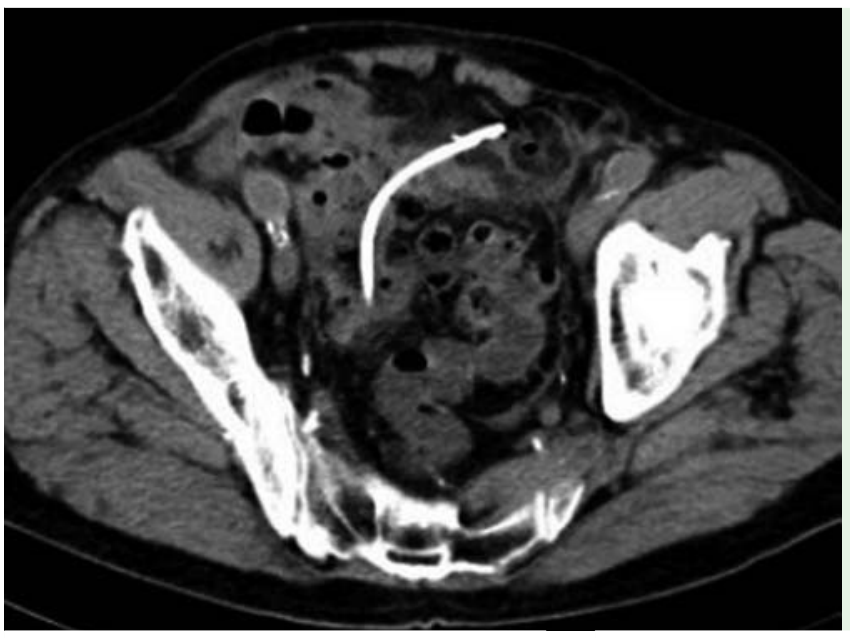

Fig. 1 Computed tomography (CT) scan in a 73-year-old man with sharp tenderness in the left iliac fossa, peritonitis, fever, and leukocytosis following endoscopic retrograde cholangiography. The scan shows a biliary stent perforating the sigmoid colon.

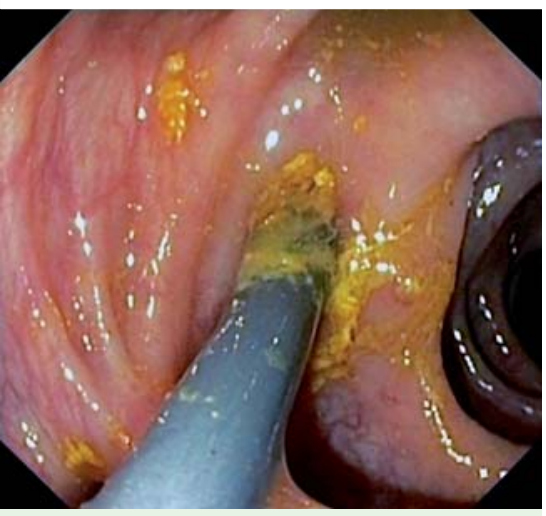

Fig. 2 Endoscopic image of the biliary stent embedded in the wall of the sigmoid colon.

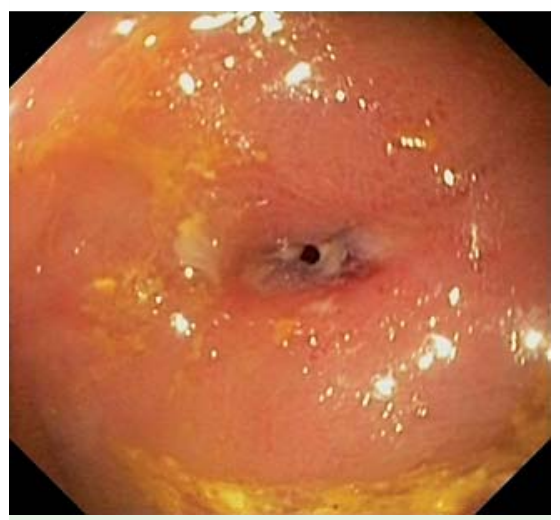

Fig.3 A small punctate perforation was seen after removal of the biliary stent.

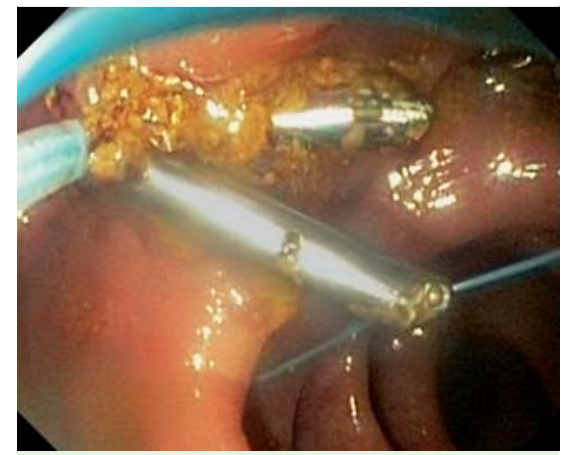

Fig. 4 Completed closure was achieved with deployment of two clips and one endoloop.

Endoscopy_UCTN_Code_CPL_1AK_2AI

Competing interests: None

\section{N. Alcaide, S. Lorenzo-Pelayo, \\ M. T. Herranz-Bachiller, \\ C. de la Serna-Higuera, J. Barrio, M. Perez-Miranda}

Gastrointestinal Endoscopy Unit, Department of Gastroenterology, University Hospital Rio Hortega, Valladolid, Spain

\section{References}

1 Anderson EM, Phillips-Hughes J, Chapman R. Sigmoid colonic perforation and pelvic abscess complicating biliary stent migration. Abdom Imaging 2007; 32: 317-319

2 Namdar T, Raffel AM, Topp SA et al. Complications and treatment of migrated biliary endoprostheses: a review of the literature. World J Gastroenterol 2007; 13: 5397-5399

3 Diller R, Senninger N, Kautz G et al. Stent migration necessitating surgical intervention. Surg Endosc 2003; 17: 1803 - 1807

4 Yoshida EM, Steinbrecher UP. Abdominal pain and rectal bleeding as a complication of biliary stent migration in a liver transplant recipient. Gastrointest Endosc 1998; 47: $418-420$

5 Ruffolo TA, Lehman GA, Sherman S et al. Biliary stent migration with colonic diverticular impaction. Gastrointest Endosc 1992; 38: $81-83$

\section{Bibliography}

Dol http://dx.doi.org/

10.1055/s-0032-1309719

Endoscopy 2012; 44: E274

(c) Georg Thieme Verlag KC

Stuttgart · New York

ISSN 0013-726X

\section{Corresponding author}

\section{N. Alcaide}

Department of Gastroenterology

University Hospital Río Hortega

C/Dulzaina 2

47012 Valladolid

Spain

noelialcaide@hotmail.com 